\title{
A randomized, double-blind, active control, multicenter, dose- finding study of lipegfilgrastim (XM22) in breast cancer patients receiving myelosuppressive therapy
}

\author{
Anton Buchner • Reiner Elsässer • Peter Bias
}

Received: 11 June 2014/ Accepted: 30 August 2014/Published online: 27 September 2014

(C) The Author(s) 2014. This article is published with open access at Springerlink.com

\begin{abstract}
This dose-ranging study was conducted to identify the optimal fixed dose of lipegfilgrastim compared with pegfilgrastim $6.0 \mathrm{mg}$ for the provision of neutrophil support during myelosuppressive chemotherapy in patients with breast cancer. A phase 2 study was conducted in which 208 chemotherapy-naive patients were randomized to receive lipegfilgrastim $3.0,4.5$, or $6.0 \mathrm{mg}$ or pegfilgrastim $6.0 \mathrm{mg}$. Study drugs were administered as a single subcutaneous injection on day 2 of each chemotherapy cycle (doxorubicin/docetaxel on day 1 for four 3-week cycles). The primary outcome measure was duration of severe neutropenia (DSN) in cycle 1. Patients treated with lipegfilgrastim experienced shorter DSN in cycle 1 with higher doses. The mean DSN was 0.76 days in the lipegfilgrastim $6.0-\mathrm{mg}$ group and 0.87 days in the pegfilgrastim 6.0-mg group, with no significant differences between treatment groups. Treatment with lipegfilgrastim $6.0 \mathrm{mg}$ was consistently associated with a higher absolute neutrophil count (ANC) at nadir, shorter ANC recovery time, and a similar safety and tolerability profile compared with pegfilgrastim. This phase 2 study demonstrated that lipegfilgrastim $6.0 \mathrm{mg}$ is the optimal dose for patients with breast cancer and provides neutrophil support that is at least equivalent to the standard 6.0-mg fixed dose of pegfilgrastim.
\end{abstract}

\footnotetext{
A. Buchner $(\square) \cdot$ R. Elsässer · P. Bias

Biosimilars Clinical Development, Teva Ratiopharm/Teva

Pharmaceuticals Inc., Graf-Arco-Str. 3, D-89079 Ulm, Germany

e-mail: anton.buchner@ratiopharm.de

R. Elsässer

e-mail: reiner.elsaesser@ ratiopharm.de

P. Bias

e-mail: peter.bias@ ratiopharm.de
}

Keywords Lipegfilgrastim - Granulocyte colonystimulating factor - Neutropenia $\cdot$ Breast cancer $\cdot$ Phase 2 clinical trial

$\begin{array}{ll}\text { Abbreviations } \\ \text { AE } & \text { Adverse event } \\ \text { ANC } & \text { Absolute neutrophil count } \\ \text { AUC } & \text { Area under the concentration-time curve } \\ \text { CI } & \text { Confidence interval } \\ \mathrm{C}_{\max } & \text { Maximum serum concentration } \\ \text { DSN } & \text { Duration of severe neutropenia } \\ \text { ECOG } & \text { Eastern Cooperative Oncology Group } \\ \text { FN } & \text { Febrile neutropenia } \\ \text { G-CSF } & \text { Granulocyte colony-stimulating factor } \\ \text { ITT } & \text { Intent-to-treat } \\ \text { i.v. } & \text { Intravenous } \\ \text { PEG } & \text { Polyethylene glycol } \\ \text { PK } & \text { Pharmacokinetic } \\ \text { PP } & \text { Per-protocol } \\ \text { TEAE } & \text { Treatment-emergent adverse event } \\ \text { TEADR } & \text { Treatment-emergent adverse drug reaction } \\ \mathrm{T}_{1 / 2} & \text { Apparent terminal elimination half-life } \\ \mathrm{T}_{\mathrm{max}} & \text { Time to } \mathrm{C}_{\text {max }}\end{array}$

\section{Introduction}

Neutropenia is a frequent, dose-limiting complication in cancer patients receiving myelosuppressive chemotherapy. Patients with neutropenia have increased risk of potentially life-threatening infections that require hospitalization and treatment with intravenous (i.v.) antibiotics [1]. Consequently, patients who develop severe or febrile neutropenia (FN) during chemotherapy generally experience dose reductions or delays, which may compromise treatment success [2]. 
Granulocyte colony-stimulating factors (G-CSFs) enhance the number and function of circulating neutrophils [3]. Prophylactic G-CSF is routinely recommended for patients receiving chemotherapy regimens associated with $\geq 20 \%$ risk of $\mathrm{FN}[2,4,5]$. Individual risk factors for neutropenic complications also should be considered when assessing use of prophylactic G-CSF in patients receiving a chemotherapy regimen associated with a 10-20\% risk of FN [2, 4].

Filgrastim is the first Escherichia coli-derived nonglycosylated recombinant form of human G-CSF [6]. Pegfilgrastim (Neulasta ${ }^{\circledR}$; Amgen Inc., Thousand Oaks, CA) is created by the covalent attachment of a polyethylene glycol (PEG) moiety to filgrastim [7]. The addition of the PEG moiety extends the half-life, allowing for dosing once per chemotherapy cycle [7]. The improved dosing regimen reduces the overall number of doses required [8] and is expected to improve the quality of life of patients by decreasing the burden associated with daily dosing [9].

Lipegfilgrastim (Lonquex $^{\circledR}$; Teva Pharmaceuticals, Petach Tikva, Israel) is a once-per-cycle, glycoPEGylated recombinant human G-CSF that is approved by the European Medicines Agency for reducing the duration of neutropenia and the incidence of FN in adults treated with cytotoxic chemotherapy for malignancy (with the exception of chronic myeloid leukemia and myelodysplastic syndromes) [10]. A recent phase 3 trial demonstrated that lipegfilgrastim was as effective as pegfilgrastim in reducing neutropenia in patients with breast cancer receiving myelosuppressive chemotherapy [11].

The primary objective of this dose-ranging phase 2 study was to compare lipegfilgrastim with a 6.0-mg dose of pegfilgrastim to identify the optimal fixed dose of lipegfilgrastim to reduce the duration of severe neutropenia (DSN) in patients with primary breast cancer receiving myelosuppressive chemotherapy with doxorubicin and docetaxel.

\section{Methods}

\section{Study design}

This multinational, multicenter, double-blind study conducted between June 2008 and November 2008 included 229 patients screened and enrolled at 37 centers in the Czech Republic, Germany, Hungary, Romania, Russia, and Ukraine. The study was designed in accordance with therapeutic guidelines and recommendations proposed by the American Society of Clinical Oncology [5], in line with current relevant guidelines from the European Society of Medical Oncology [12] and European Medicines Agency [13], and was conducted in accordance with the
Declaration of Helsinki and the International Conference on Harmonisation guidance for Good Clinical Practice. It was approved by local institutional review boards/independent ethics committees of participating centers. A written informed consent was obtained from all patients.

This 12-week double-blind study comprised four 3-week chemotherapy cycles. Patients were randomized $1: 1: 1: 1$ to receive $3.0,4.5$, or $6.0 \mathrm{mg}$ lipegfilgrastim or $6.0 \mathrm{mg}$ pegfilgrastim subcutaneously on chemotherapy day $2(\approx 24 \mathrm{~h}$ after start of chemotherapy). Lipegfilgrastim doses were based on phase 1 results in which dosing was adjusted based on the body weight of patients. Patients were randomized in blocks and stratified by country, reason for chemotherapy (adjuvant therapy/metastatic disease), and body weight.

A true double-blind design was not feasible because lipegfilgrastim was provided in vials and pegfilgrastim in prefilled syringes; therefore, study drug was administered by qualified, unblinded personnel. Every effort was made to ensure that patients remained blinded. Investigators were kept blinded and performed all patient assessments without any knowledge of treatment assignment.

\section{Patients}

Male and female patients $\geq 18$ years of age with high-risk stage II, III, or IV breast cancer (according to the American Joint Committee on Cancer [14]) were eligible if they had an Eastern Cooperative Oncology Group (ECOG) performance status $\leq 2$; absolute neutrophil count (ANC) $\geq 1.5 \times 10^{9} / \mathrm{L} ;$ platelet count $\geq 100 \times 10^{9} / \mathrm{L}$; and adequate cardiac, hepatic, and renal function. Patients had to be chemotherapy-naive and eligible for or scheduled to receive doxorubicin/docetaxel as routine chemotherapy.

Exclusion criteria included previous G-CSF exposure, known docetaxel hypersensitivity, $\geq$ grade 2 underlying neuropathy, treatment with systemically active antibiotics within $72 \mathrm{~h}$ before chemotherapy, treatment with lithium, chronic oral corticosteroid use, or radiation therapy within 4 weeks of randomization, prior bone marrow or stem cell transplantation, or malignancy within 5 years. Also excluded were pregnant or breastfeeding women and women of childbearing potential who did not agree to use an effective method of contraception.

\section{Chemotherapy treatment}

Chemotherapy consisted of doxorubicin $60 \mathrm{mg} / \mathrm{m}^{2}$ given as an i.v. bolus injection followed $1 \mathrm{~h}$ later by a 1-h i.v. infusion of docetaxel $75 \mathrm{mg} / \mathrm{m}^{2}$. Treatment was repeated every 21 days for up to four cycles. To begin full-dose chemotherapy on day 1 of the next cycle (day 22 of previous cycle), ANC must have recovered to $\geq 1.5 \times 10^{9} / \mathrm{L}$ 
and platelet counts to $\geq 100 \times 10^{9} / \mathrm{L}$. If these requirements were not met, postponement of the following cycle for up to 2 weeks was acceptable. Both ANC and platelets were determined on day 15 of each cycle by a central laboratory (EurofinsMedinet, The Netherlands) so that results were available at the beginning of the next cycle.

In patients who experienced $\mathrm{FN}$ and/or ANC $<0.5 \times$ $10^{9} / \mathrm{L}$ for $>1$ week, severe or cumulative cutaneous reactions, or severe (grade 3 or 4) peripheral neuropathy during therapy, the dose of docetaxel was reduced by $20 \%$. Doxorubicin was reduced by $25 \%$ in patients with $\mathrm{FN}$ and/ or ANC $<0.5 \times 10^{9} / \mathrm{L}$ for $>1$ week. In patients with a platelet count of $<20 \times 10^{9} / \mathrm{L}$ and/or failure to recover to $\geq 100 \times 10^{9} / \mathrm{L}$ by day 21 of a cycle, dosages of doxorubicin and docetaxel had to be reduced by $25 \%$ in subsequent cycles. If reactions continued at the reduced chemotherapy doses, study treatment was discontinued and the patient was withdrawn.

\section{Efficacy measurements}

Blood samples for ANC were collected within $24 \mathrm{~h}$ before chemotherapy in cycle 1 , then daily from day 2 (before study drug administration) through day 15 , until the ANC reached $\geq 2.0 \times 10^{9} / \mathrm{L}$, or the patient was able to enter the next chemotherapy cycle (ANC $\geq 1.5 \times 10^{9} / \mathrm{L}$ on day 1 of the next cycle). In cycles $2-4$, ANC assessments began on day 5 . A similar schedule was used for measuring body temperature with a calibrated standard device. Blood ANC samples in efficacy analyses were analyzed by local laboratories.

The primary efficacy measure was the DSN, defined as days with grade 4 neutropenia (ANC $<0.5 \times 10^{9} / \mathrm{L}$ ) in cycle 1 . Secondary efficacy measures included DSN in cycles 2, 3, and 4; incidence of FN, defined as axillary body temperature $>38.5^{\circ} \mathrm{C}$ for $>1 \mathrm{~h}$ and ANC $<0.5 \times$ $10^{9} / \mathrm{L}$ in cycles $1,2,3$, and 4 and across all cycles; incidence of severe neutropenia (grade 4; ANC $<0.5 \times$ $10^{9} / \mathrm{L}$ ) in cycles $1,2,3$, and 4 ; depth of ANC nadir; time to ANC recovery (the first day with ANC $\geq 2.0 \times 10^{9} / \mathrm{L}$ after any day with $\mathrm{ANC}<2.0 \times 10^{9} / \mathrm{L}$ ); and median ANC time profiles.

\section{Pharmacokinetic analysis}

Blood samples for pharmacokinetic (PK) analysis were taken from a subpopulation of 33 patients $(6.0-\mathrm{mg}$ pegfilgrastim group, $n=7 ; 3.0,4.5$, and $6.0-\mathrm{mg}$ lipegfilgrastim groups, $n=11, n=7$, and $n=8$, respectively) from selected centers in cycles 1 and 4. Samples were collected predose, 2, 4, and $8 \mathrm{~h}$ after study drug administration on day 2 , and on days $3,4,5,6,7,8,9,12$, and 15. Lipegfilgrastim and pegfilgrastim serum concentrations were analyzed using a validated quantitative sandwich immunoassay in compliance with good laboratory practice at Cirion Biopharma Research Inc. (Laval, Quebec, Canada). Standard PK parameters (area under the concentration-time curve [AUC], maximum serum concentration [ $C_{\max }$ ], time to $C_{\max }\left[T_{\max }\right.$ ], apparent terminal elimination half-life $\left[T_{1 / 2}\right], \mathrm{AUC}_{0 \text {-inf }}$ and $\mathrm{AUC}_{0 \text {-last }}$ ) were calculated by noncompartmental methods using WinNonlin 6.0 (Pharsight Corporation, St. Louis, MO).

\section{Safety assessments}

An independent data safety monitoring committee monitored unexpected side effects. All adverse events (AEs) were reported until 30 days after the last study drug injection. Each $\mathrm{AE}$ was assessed by the investigator as serious or non-serious. A serious AE was one that resulted in death, was life-threatening, required inpatient hospitalization or prolongation of existing hospitalization, resulted in persistent or significant disability/incapacity, was a congenital anomaly/birth defect, or was an important medical event that jeopardized the patient or required medical intervention to prevent one of the previously listed criteria. Safety assessments-which included blood samples for antibody determination, physical examinations, and vital signs-were performed within $24 \mathrm{~h}$ before chemotherapy in each cycle and at end of study. Blood samples for assessment of laboratory safety parameters (hematology, platelets, and clinical chemistry) were collected at baseline, on day 15 of each cycle, and at end of study. All grade 3 and 4 non-hematologic toxicities and all grade 4 hematologic toxicities (except white blood cell counts and differential count) were considered AEs.

\section{Statistical analysis}

Summary statistics were calculated for each measure. Poisson regression analyses, including treatment, region (Eastern and Central Europe versus Russia and Ukraine), type of therapy (adjuvant versus treatment for metastatic disease), weight class $(\leq 60,>60$ to $\leq 75,>75 \mathrm{~kg})$, and baseline ANC as covariates, were performed for primary and secondary DSN measures as well as for ANC nadir and recovery end points. In relation to incidence of neutropenia, logistic regression analyses were performed with the same cofactors used for Poisson regression analyses. For mean DSN and secondary end points, 2-sided $95 \%$ confidence intervals (CIs) were calculated for the ratios of expected values and for the odds ratios of all possible comparisons between treatment groups. Chi-squared tests were used to compare AEs among all four treatment groups, and the Cochran-Armitage Trend test scrutinized possible dose dependencies among lipegfilgrastim dose groups. 
A post-hoc efficacy analysis assessed non-inferiority of the lipegfilgrastim dose groups versus the pegfilgrastim group for DSN in cycle 1. Poisson regression analyses with identity link and analysis of covariance with possible heteroskedasticity, including treatment, region, therapy type, weight class, and baseline ANC as covariates, were performed. Bonferroni-adjusted 2-sided $98.3 \%$ CIs were calculated for least-squares mean differences in DSN in cycle 1 for lipegfilgrastim versus pegfilgrastim. The equivalence margin was set to \pm 1 day.

The number of patients per treatment group was not based on formal statistical sample-size calculations but was considered adequate to allow for determination of an optimal lipegfilgrastim dose for phase 3 clinical studies. In a previous study conducted in patients with breast cancer treated with XM02 (Tevagrastim ${ }^{\circledR}$, Ratiograstim ${ }^{\circledR}$, Biograstim $^{\circledR}$, and Granix ${ }^{\mathrm{TM}}$, Teva Pharmaceutical Industries Ltd., Petach Tikva, Israel) or Neupogen ${ }^{\circledR}$ (Amgen, Thousand Oaks, CA, USA), a mean DSN of 1.1 days and a standard deviation of 1.2 were observed in cycle 1 for both drugs [15]. Assuming the same numbers for one of the lipegfilgrastim groups and the pegfilgrastim group in the present study, the 2 -sided $95 \%$ CI for the difference in mean DSN between these 2 groups would have a maximal width of \pm 0.5 with about $80 \%$ probability. A Poisson regression model for the previous study estimated the variance to be about 1.25 times the mean. Thus, a mean DSN of 0.5 would correspond to a standard deviation of 0.8 , and a mean DSN of 2.0 would correspond to a standard deviation of 1.6. Assuming the same relationship between mean and variance in the present study, the difference between 2 groups with mean DSN of 0.5 and 1.1 could be detected with a power of $83 \%$, whereas the difference between 2 groups with mean DSN of 1.1 and 2.0 could be detected with a power of $88 \%$, both at the 2 -sided $5 \%$ level.

\section{Analysis populations}

Demographic and baseline characteristics, efficacy variables, and post-hoc non-inferiority tests were evaluated for the intent-to-treat (ITT) and per-protocol (PP) populations. The full analysis population (ITT) comprised all patients randomized to a study drug at the baseline visit. The PP population comprised all patients in the ITT set who completed $\geq 1$ cycle of chemotherapy, received $\geq 1$ dose of study drug, and had no major protocol violations. The safety population included all randomized patients who received $\geq 1$ dose of study medication and was identical to the ITT population. The PK population comprised patients from selected centers who had blood samples collected for PK analysis in cycles 1 and 4.

\section{Results}

Study population

A total of 208 patients were randomized; 202 (97.1\%) completed the study (Fig. 1). Of the 6 patients who withdrew from the study, 3 withdrew because of AEs, 2 withdrew consent, and 1 was lost to follow-up. All 208 randomized patients were treated with study drug and were eligible for efficacy and safety analyses. Three patients had major protocol violations ( 1 received the wrong study drug dose and 2 received the wrong chemotherapy doses) and were included in the ITT and safety populations only.

Demographic and baseline disease characteristics were similar among treatment groups, with the majority of patients having stage III $(46.2 \%)$ or high-risk stage II disease $(38.5 \%$; Tables 1,2$)$. The majority of patients were aged $<65$ years and had ECOG performance status of 0 or 1 .

Results in the PP population were similar to those in the ITT population.

\section{Efficacy}

\section{Duration of severe neutropenia in cycle 1}

There was no significant difference in the DSN for cycle 1 among the 3 lipegfilgrastim doses, or between the lipegfilgrastim doses and the pegfilgrastim dose (Table 3). The DSN in cycle 1 was consistently approximately 1 day or less, with a pooled DSN of 0.89 days. The percentage of patients who did not experience severe neutropenia was higher in the lipegfilgrastim 6.0-mg group (62.0\%) compared with the lipegfilgrastim 3.0- and 4.5-mg groups and the pegfilgrastim group (43.4, 49.0, and $46.3 \%$, respectively).

Post-hoc analyses established non-inferiority of lipegfilgrastim to pegfilgrastim for DSN in cycle 1 . All three $98.3 \%$ 2-sided CIs for least-squares mean differences between lipegfilgrastim and pegfilgrastim were included in the equivalence region between -1 and +1 day. The upper limit of the $98.3 \%$ 2-sided CI for the difference between lipegfilgrastim and pegfilgrastim was 0.28 days for lipegfilgrastim $6.0 \mathrm{mg}, 0.29$ days for lipegfilgrastim $4.5 \mathrm{mg}$, and 0.72 days for lipegfilgrastim $3.0 \mathrm{mg}$.

\section{Duration of severe neutropenia in cycles 2-4}

Mean DSN was consistently shorter in cycles 2-4 versus cycle 1 in all treatment groups (Table 3 ). In the pooled treatment group, $\geq 80 \%$ of patients did not experience severe neutropenia in cycles 2-4. However, incidence of severe neutropenia was lower in the lipegfilgrastim groups 
Fig. 1 Patient disposition. $A E$ adverse event

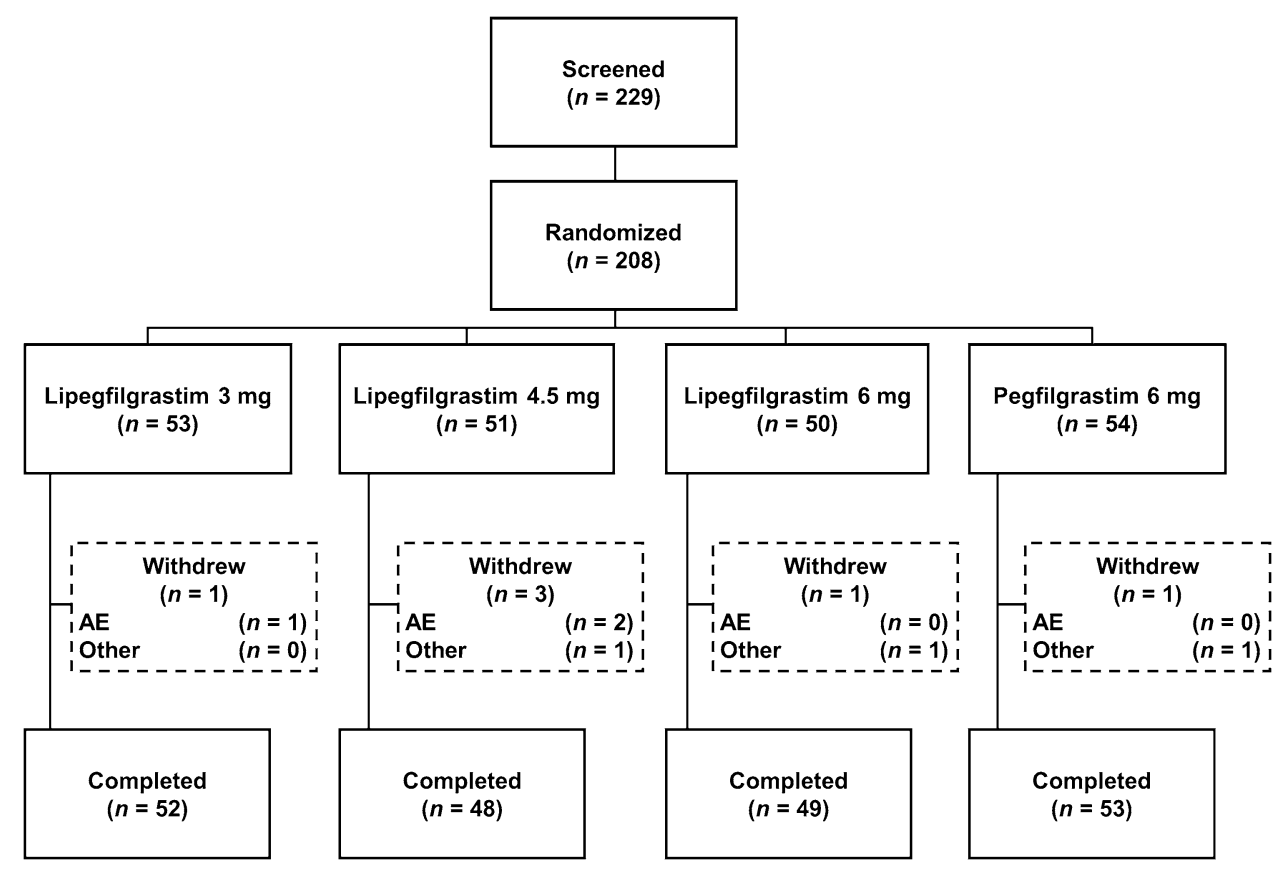

\begin{tabular}{|c|c|c|c|c|}
\hline \multirow[t]{2}{*}{ Characteristic } & \multicolumn{3}{|c|}{ Lipegfilgrastim } & \multirow{2}{*}{$\begin{array}{l}\text { Pegfilgrastim } \\
6.0 \mathrm{mg}(n=54)\end{array}$} \\
\hline & $\begin{array}{l}3.0 \mathrm{mg} \\
(n=53)\end{array}$ & $\begin{array}{l}4.5 \mathrm{mg} \\
(n=51)\end{array}$ & $\begin{array}{l}6.0 \mathrm{mg} \\
(n=50)\end{array}$ & \\
\hline \multicolumn{5}{|l|}{ Age (years) } \\
\hline Mean $\pm \mathrm{SD}$ & $53.1 \pm 9.2$ & $52.8 \pm 10.1$ & $51.4 \pm 9.8$ & $49.5 \pm 11.1$ \\
\hline$\leq 64, n(\%)$ & $46(86.8)$ & $45(88.2)$ & $45(90.0)$ & $50(92.6)$ \\
\hline $65-74, n(\%)$ & $7(13.2)$ & $6(11.8)$ & $5(10.0)$ & $4(7.4)$ \\
\hline \multicolumn{5}{|l|}{ Weight (kg) } \\
\hline Mean \pm SD & $70.6 \pm 13.1$ & $70.6 \pm 14.8$ & $74.5 \pm 19.7$ & $71.2 \pm 13.2$ \\
\hline$\leq 60, n(\%)$ & $12(22.6)$ & $13(25.5)$ & $13(26.0)$ & $14(25.9)$ \\
\hline$>60-\leq 75, n(\%)$ & $24(45.3)$ & $20(39.2)$ & $19(38.0)$ & $18(33.3)$ \\
\hline$>75, n(\%)$ & $17(32.1)$ & $18(35.3)$ & $18(36.0)$ & $22(40.7)$ \\
\hline \multicolumn{5}{|l|}{ Gender, $n(\%)$} \\
\hline Female & $52(98.1)$ & $50(98.0)$ & $50(100.0)$ & $53(98.1)$ \\
\hline Male & $1(1.9)$ & $1(2.0)$ & $0(0)$ & $1(1.9)$ \\
\hline \multicolumn{5}{|l|}{ Reason for chemotherapy, $n(\%)$} \\
\hline Adjuvant therapy & $43(81.1)$ & $44(86.3)$ & $41(82.0)$ & $43(79.6)$ \\
\hline Treatment for metastatic disease & $10(18.9)$ & $7(13.7)$ & $9(18.0)$ & $11(20.4)$ \\
\hline
\end{tabular}

Table 1 Summary of patient demographic characteristics (intent-to-treat population)

\section{$S D$ standard deviation}

compared with the pegfilgrastim group for each chemotherapy cycle. Mean DSN was significantly $(P \leq 0.023)$ shorter in the lipegfilgrastim 6.0-mg group versus the pegfilgrastim group for chemotherapy cycles 2,3 , and 4 .

\section{Incidence of observed febrile neutropenia or severe neutropenia}

Only one patient in the pegfilgrastim group experienced $\mathrm{FN}$ incycle 1. The incidence of severe (grade 4) neutropenia was highest in cycle 1: $56.6 \%$ with lipegfilgrastim $3.0 \mathrm{mg}, 51.0 \%$ with lipegfilgrastim $4.5 \mathrm{mg}, 38.0 \%$ with lipegfilgrastim $6.0 \mathrm{mg}$, and $53.7 \%$ with pegfilgrastim $6.0 \mathrm{mg}$. In all cycles, incidence of severe neutropenia was lower with lipegfilgrastim 4.5 and $6.0 \mathrm{mg}$ versus pegfilgrastim and lipegfilgrastim $3.0 \mathrm{mg}$ (data not shown), reaching significance versus pegfilgrastim in chemotherapy cycles 2,3 , and $4(P<0.05)$.

\section{Absolute neutrophil count profiles}

A dose-dependent trend was observed for ANC nadir values, with lipegfilgrastim $6.0 \mathrm{mg}$ being the most 
Table 2 Characteristics of breast cancer (intent-to-treat population)

ECOG Eastern Cooperative Oncology Group, $S D$ standard deviation

ECOG performance status: 0, fully active, able to carry on all predisease performance without restriction; 1 , restricted in physically strenuous activity but ambulatory and able to carry out work of a light or sedentary nature, e.g., light housework, office work; 2, ambulatory and capable of all self-care but unable to carry out any work activities; up and about $>50 \%$ of waking hours

Table 3 Duration of severe neutropenia, incidence of severe neutropenia, depth of ANC nadir, and time to ANC recovery (intent-to-treat population)

ANC absolute neutrophil count, $D S N$ duration of severe neutropenia, $S D$ standard deviation

a $P \leq 0.01$ versus pegfilgrastim

b $P \leq 0.05$ versus pegfilgrastim

c $P \leq 0.001$ versus pegfilgrastim

\begin{tabular}{llll}
\hline Parameter & Lipegfilgrastim & & $\begin{array}{l}\text { Pegfilgrastim 6.0 } \\
\mathrm{mg}(n=54)\end{array}$ \\
\cline { 2 - 4 } $3.0 \mathrm{mg}(n=53)$ & $4.5 \mathrm{mg}(n=51)$ & $6.0 \mathrm{mg}(n=50)$ & \\
\hline
\end{tabular}

Stage $n(\%)$

$\begin{array}{lllll}\text { High-risk stage II } & 21(39.6) & 19(37.3) & 18(36.0) & 22(40.7) \\ \text { Stage III } & 23(43.4) & 26(51.0) & 24(48.0) & 23(42.6) \\ \text { Stage IV } & 9(17.0) & 6(11.8) & 8(16.0) & 9(16.7) \\ \text { Tumor location, } n(\%) & & & & \\ \text { Left } & 19(35.8) & 25(49.0) & 22(44.0) & 26(48.1) \\ \text { Right } & 31(58.5) & 25(49.0) & 27(54.0) & 27(50.0) \\ \text { Both } & 3(5.7) & 1(2.0) & 1(2.0) & 1(1.9)\end{array}$

ECOG performance status, $n(\%)$

$\begin{array}{lllll}0 & 34(64.2) & 26(51.0) & 28(56.0) & 33(61.1) \\ 1 & 18(34.0) & 22(43.1) & 21(42.0) & 21(38.9) \\ 2 & 1(1.9) & 3(5.9) & 1(2.0) & 0(0)\end{array}$

Time since first diagnosis (months)

$\begin{array}{lllll}\text { Mean } \pm \text { SD } & 0.9 \pm 0.9 & 5.4 \pm 25.9 & 2.9 \pm 10.2 & 16.1 \pm 50.7 \\ \text { Median } & 1.0 & 1.0 & 1.0 & 1.0 \\ \text { Range } & 0.0-4.0 & 0.0-184.0 & 0.0-65.0 & 0.0-259.0\end{array}$

\begin{tabular}{|c|c|c|c|c|}
\hline \multirow[t]{2}{*}{ Parameter } & \multicolumn{3}{|c|}{ Lipegfilgrastim } & \multirow{2}{*}{$\begin{array}{l}\text { Pegfilgrastim } \\
6.0 \mathrm{mg} \\
(n=54)\end{array}$} \\
\hline & $\begin{array}{l}3.0 \mathrm{mg} \\
(n=53)\end{array}$ & $\begin{array}{l}4.5 \mathrm{mg} \\
(n=51)\end{array}$ & $\begin{array}{l}6.0 \mathrm{mg} \\
(n=50)\end{array}$ & \\
\hline \multicolumn{5}{|l|}{ Cycle 1 DSN (days) } \\
\hline Mean $\pm \mathrm{SD}$ & $1.08 \pm 1.12$ & $0.84 \pm 1.05$ & $0.76 \pm 1.10$ & $0.87 \pm 0.99$ \\
\hline Median (range) & $1.0(0.0-4.0)$ & $1.0(0.0-4.0)$ & $0.0(0.0-3.0)$ & $1.0(0.0-3.0)$ \\
\hline \multicolumn{5}{|l|}{ Mean DSN \pm SD (days) } \\
\hline Cycle 2 & $0.32 \pm 0.70$ & $0.14 \pm 0.49^{\mathrm{a}}$ & $0.18 \pm 0.39^{\mathrm{b}}$ & $0.41 \pm 0.63$ \\
\hline Cycle 3 & $0.30 \pm 0.67$ & $0.20 \pm 0.80$ & $0.12 \pm 0.39^{\mathrm{b}}$ & $0.35 \pm 0.71$ \\
\hline Cycle 4 & $0.23 \pm 0.51^{\mathrm{b}}$ & $0.22 \pm 0.78^{\mathrm{b}}$ & $0.12 \pm 0.44^{\mathrm{a}}$ & $0.48 \pm 0.91$ \\
\hline \multicolumn{5}{|c|}{ Cycle 1: Incidence by duration [days], $n(\%)$} \\
\hline 0 & $23(43.4)$ & $25(49.0)$ & $31(62.0)$ & $25(46.3)$ \\
\hline 1 & $10(18.9)$ & $15(29.4)$ & $6(12.0)$ & $16(29.6)$ \\
\hline 2 & $14(26.4)$ & $6(11.8)$ & $7(14.0)$ & $8(14.8)$ \\
\hline 3 & $5(9.4)$ & $4(7.8)$ & $6(12.0)$ & $5(9.3)$ \\
\hline 4 & $1(1.9)$ & $1(2.0)$ & $0(0.0)$ & $0(0.0)$ \\
\hline Total & $53(100.0)$ & $51(100.0)$ & $50(100.0)$ & $54(100.0)$ \\
\hline \multicolumn{5}{|c|}{ Incidence of severe neutropenia, $n(\%)$} \\
\hline Cycle 1 & $30(56.60)$ & $26(50.98)$ & $19(38.00)$ & $29(53.70)$ \\
\hline Cycle 2 & $11(20.75)$ & $4(7.84)^{\mathrm{c}}$ & $9(18.00)^{\mathrm{b}}$ & $18(33.96)$ \\
\hline Cycle 3 & $10(18.87)$ & $3(6.00)^{\mathrm{a}}$ & $5(10.00)^{b}$ & $13(24.53)$ \\
\hline Cycle 4 & $9(17.31)$ & $4(8.33)^{\mathrm{b}}$ & $4(8.00)^{\mathrm{b}}$ & $14(26.42)$ \\
\hline $\begin{array}{l}\text { Cycle 1: Mean depth of ANC } \\
\text { nadir } \pm \mathrm{SD}, 10^{9} / \mathrm{L}\end{array}$ & $0.86 \pm 1.08$ & $1.33 \pm 1.66$ & $1.67 \pm 1.99^{c}$ & $0.93 \pm 1.30$ \\
\hline $\begin{array}{l}\text { Cycle 1: mean time to ANC } \\
\text { recovery } \pm \mathrm{SD} \text {, days }\end{array}$ & $7.32 \pm 3.07$ & $6.10 \pm 3.92$ & $5.80 \pm 3.96^{\mathrm{b}}$ & $7.44 \pm 3.01$ \\
\hline
\end{tabular}


Fig. 2 Median absolute neutrophil count time profiles in cycle 1

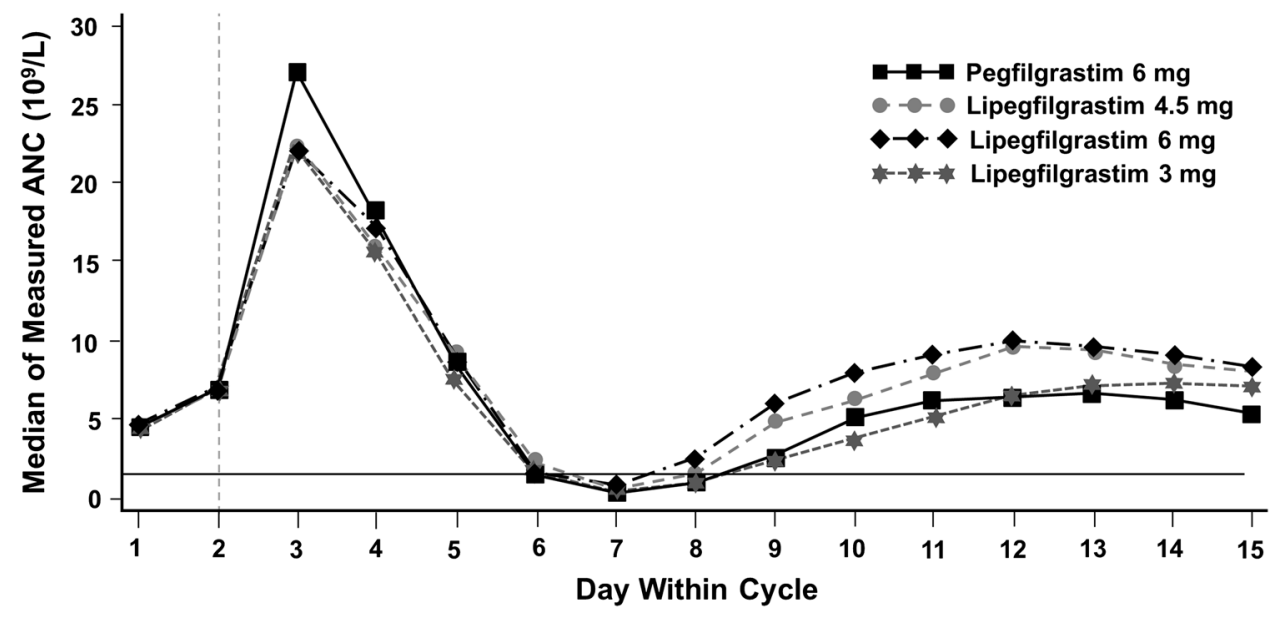

Table 4 Summary of pharmacokinetic (PK) parameters by treatment and cycle (PK population)

\begin{tabular}{|c|c|c|c|c|c|}
\hline \multirow[t]{2}{*}{ Parameter (mean) } & \multirow[t]{2}{*}{ Cycle } & \multicolumn{3}{|l|}{ Lipegfilgrastim } & \multirow[t]{2}{*}{ Pegfilgrastim $6.0 \mathrm{mg}(n=7)$} \\
\hline & & $3.0 \mathrm{mg}(n=11)$ & $4.5 \mathrm{mg}\left(n=7^{\mathrm{c}}\right)$ & $6.0 \mathrm{mg}(n=8)$ & \\
\hline \multirow[t]{2}{*}{$C_{\max }, \mathrm{ng} / \mathrm{mL}^{\mathrm{a}}$} & 1 & 44.91 & 142.71 & 156.74 & 138.61 \\
\hline & 4 & 24.37 & 47.90 & 36.24 & 42.71 \\
\hline \multirow[t]{2}{*}{$\mathrm{AUC}_{0 \text {-last }}, \mathrm{ng} / / \mathrm{mL} \bullet \mathrm{h}^{\mathrm{a}}$} & 1 & 3475.8 & $11,880.1$ & $13,328.2$ & 8613.0 \\
\hline & 4 & 1416.1 & 2959.7 & 2632.1 & 2598.4 \\
\hline \multirow[t]{2}{*}{$\mathrm{AUC}_{0-\mathrm{inf}}, \mathrm{ng} / \mathrm{mL} \bullet \mathrm{h}^{\mathrm{a}}$} & 1 & 3496.4 & 9608.7 & $13,342.3$ & 8623.5 \\
\hline & 4 & 1424.4 & 2980.8 & 2657.0 & 2607.5 \\
\hline \multirow[t]{2}{*}{$T_{\max }, \mathrm{h}^{\mathrm{b}}$} & 1 & 52.2 & 59.0 & 53.0 & 17.7 \\
\hline & 4 & 22.5 & 16.0 & 11.4 & 23.4 \\
\hline \multirow[t]{2}{*}{$T_{1 / 2}, \mathrm{~h}^{\mathrm{b}}$} & 1 & 36.7 & 31.2 & 29.3 & 29.5 \\
\hline & 4 & 35.4 & 32.0 & 38.9 & 29.6 \\
\hline
\end{tabular}

$A U C_{0 \text {-last }}$ area under the concentration-time curve from predose on day 2 to last observed concentration value above the lower limit of quantification, $A U C_{0-\text { inf }}$ area under the concentration-time curve from predose on day 2 to infinity, $C_{\max }$ maximum serum concentration, $h$ hours, $T_{1 / 2}$ apparent terminal elimination half-life, $T_{\max }$ time to maximum serum concentration

a Results for $C_{\max }, \mathrm{AUC}_{0 \text {-last }}$, and $\mathrm{AUC}_{0 \text {-inf }}$ are geometric means

b Results for $T_{\max }$ and $T_{1 / 2}$ are arithmetic means

c $N=6$ for all parameters in cycle 4 and for $\mathrm{AUC}_{0 \text {-inf }}$ and $T_{1 / 2}$ in cycle 1

effective dose and the only dose where the depth of ANC nadir was significantly higher versus pegfilgrastim for all chemotherapy cycles $(P \leq 0.05)$. Some significant trends indicated longer time to ANC nadir with higher lipegfilgrastim doses $(P<0.05$ for cycles 1,3 , and 4$)$. Time to ANC recovery was shortest with lipegfilgrastim $6.0 \mathrm{mg}$, for which ANC recovery times were significantly shorter versus pegfilgrastim in all chemotherapy cycles $(P<0.05)$. The course of median ANC over time in cycle 1 is shown in Fig. 2.

\section{Pharmacokinetics}

Pharmacokinetic parameters are summarized in Table 4 . Lipegfilgrastim serum concentrations in cycle 1 peaked at approximately $48 \mathrm{~h}$ and returned to predose levels within $240 \mathrm{~h}$. A dose-dependent trend was evident for most PK parameters, with mean values for the lipegfilgrastim 6.0and $4.5-\mathrm{mg}$ doses being higher versus pegfilgrastim (Table 4). Lipegfilgrastim $T_{\max }$ was notably higher than pegfilgrastim in cycle 1 , but by cycle 4 , influenced by neutrophil-dependent elimination, $T_{\max }$ for lipegfilgrastim was closer to pegfilgrastim.

Safety

Adverse events were similar among treatment groups, with no dose-dependent lipegfilgrastim trend (Table 5). The overall frequency of AEs decreased with each chemotherapy cycle. The most commonly occurring AEs (total 
Table 5 Most frequent adverse events by preferred term occurring in $\geq 5$ patients overall (safety population)
MedDRA Medical Dictionary for Regulatory Activities

\begin{tabular}{|c|c|c|c|c|c|}
\hline \multirow{2}{*}{$\begin{array}{l}\text { MedDRA preferred } \\
\text { term, } n(\%)\end{array}$} & \multicolumn{3}{|c|}{ Lipegfilgrastim } & \multirow{2}{*}{$\begin{array}{l}\text { Pegfilgrastim } 6.0 \mathrm{mg} \\
(n=54)\end{array}$} & \multirow{2}{*}{$\begin{array}{l}\text { Pooled } \\
(N=208)\end{array}$} \\
\hline & $\begin{array}{l}3.0 \mathrm{mg} \\
(n=53)\end{array}$ & $\begin{array}{l}4.5 \mathrm{mg} \\
(n=51)\end{array}$ & $\begin{array}{l}6.0 \mathrm{mg} \\
(n=50)\end{array}$ & & \\
\hline Alopecia & $25(47.2)$ & $23(45.1)$ & $27(54.0)$ & $24(44.4)$ & 99 (47.6) \\
\hline Nausea & $21(39.6)$ & $20(39.2)$ & $22(44.0)$ & $25(46.3)$ & $88(42.3)$ \\
\hline Asthenia & 12 (22.6) & $16(31.4)$ & $14(28.0)$ & $9(16.7)$ & $51(24.5)$ \\
\hline Bone pain & $9(17.0)$ & 9 (17.6) & $10(20.0)$ & $12(22.2)$ & $40(19.2)$ \\
\hline Diarrhea & $7(13.2)$ & 11 (21.6) & $13(26.0)$ & $7(13.0)$ & $38(18.3)$ \\
\hline Fatigue & $9(17.0)$ & 7 (13.7) & $8(16.0)$ & $13(24.1)$ & 37 (17.8) \\
\hline Anorexia & $6(11.3)$ & $13(25.5)$ & $9(18.0)$ & $7(13.0)$ & $35(16.8)$ \\
\hline Vomiting & $7(13.2)$ & $6(11.8)$ & $5(10.0)$ & $10(18.5)$ & $28(13.5)$ \\
\hline Headache & $6(11.3)$ & 7 (13.7) & $5(10.0)$ & $4(7.4)$ & $22(10.6)$ \\
\hline Myalgia & $5(9.4)$ & $6(11.8)$ & $7(14.0)$ & $3(5.6)$ & $21(10.1)$ \\
\hline Stomatitis & $5(9.4)$ & $4(7.8)$ & $6(12.0)$ & $4(7.4)$ & $19(9.1)$ \\
\hline Neutropenia & $3(5.7)$ & $5(9.8)$ & $4(8.0)$ & $3(5.6)$ & $15(7.2)$ \\
\hline Arthralgia & $4(7.5)$ & $5(9.8)$ & $2(4.0)$ & $2(3.7)$ & $13(6.3)$ \\
\hline Tachycardia & $4(7.5)$ & $2(3.9)$ & $3(6.0)$ & $3(5.6)$ & $12(5.8)$ \\
\hline Abdominal pain upper & $4(7.5)$ & $1(2.0)$ & $3(6.0)$ & $2(3.7)$ & $10(4.8)$ \\
\hline Thrombocytopenia & 0 & $6(11.8)$ & $2(4.0)$ & $2(3.7)$ & $10(4.8)$ \\
\hline Back pain & $2(3.8)$ & $4(7.8)$ & $2(4.0)$ & $1(1.9)$ & $9(4.3)$ \\
\hline Dizziness & $2(3.8)$ & $5(9.8)$ & $1(2.0)$ & $1(1.9)$ & $9(4.3)$ \\
\hline Hypertension & $4(7.5)$ & $2(3.9)$ & $3(6.0)$ & 0 & $9(4.3)$ \\
\hline $\begin{array}{l}\text { Peripheral sensory } \\
\text { neuropathy }\end{array}$ & $1(1.9)$ & 0 & $3(6.0)$ & $4(7.4)$ & $8(3.8)$ \\
\hline $\begin{array}{l}\text { Viral respiratory tract } \\
\text { infection }\end{array}$ & $1(1.9)$ & $1(2.0)$ & $1(2.0)$ & $5(9.3)$ & $8(3.8)$ \\
\hline Febrile neutropenia & 0 & $2(3.9)$ & $3(6.0)$ & $2(3.7)$ & $7(3.4)$ \\
\hline Pharyngolaryngeal pain & 0 & $3(5.9)$ & $2(4.0)$ & $2(3.7)$ & $7(3.4)$ \\
\hline Anemia & $1(1.9)$ & $4(7.8)$ & $1(2.0)$ & 0 & $6(2.9)$ \\
\hline Constipation & 0 & $3(5.9)$ & $2(4.0)$ & $1(1.9)$ & $6(2.9)$ \\
\hline Dysgeusia & $1(1.9)$ & 0 & $1(2.0)$ & $4(7.4)$ & $6(2.9)$ \\
\hline Peripheral edema & 0 & $2(3.9)$ & $3(6.0)$ & $1(1.9)$ & $6(2.9)$ \\
\hline Abdominal pain & $1(1.9)$ & $2(3.9)$ & $2(4.0)$ & 0 & $5(2.4)$ \\
\hline Mucosal inflammation & 0 & $2(3.9)$ & 0 & $3(5.6)$ & $5(2.4)$ \\
\hline Pyrexia & $2(3.8)$ & 0 & $2(4.0)$ & $1(1.9)$ & $5(2.4)$ \\
\hline Rash & 0 & $1(2.0)$ & $2(4.0)$ & $2(3.7)$ & $5(2.4)$ \\
\hline Decreased weight & $1(1.9)$ & $1(2.0)$ & $3(6.0)$ & 0 & $5(2.4)$ \\
\hline
\end{tabular}

incidence $\geq 10 \%$ in the pooled treatment group) were: alopecia $(47.6 \%)$, nausea $(42.3 \%)$, asthenia $(24.5 \%)$, bone pain $(19.2 \%)$, diarrhea $(18.3 \%)$, fatigue $(17.8 \%)$, anorexia $(16.8 \%)$, vomiting $(13.5 \%)$, headache $(10.6 \%)$, and myalgia (10.1\%).

None of the patients died during the study. Serious AEs were reported in $10(4.8 \%)$ patients. One patient in the lipegfilgrastim 3.0-mg group experienced pyrexia; 3 patients in the lipegfilgrastim 4.5-mg group experienced gastroenteritis, paronychia, and pneumonia (one $\mathrm{AE}$ in each patient), and one patient in the 4.5-mg group experienced thrombocytopenia, FN, and mucosal inflammation. One patient in the lipegfilgrastim 6.0-mg group experienced $\mathrm{FN}$ and another patient in the 6.0-mg group experienced asthenia and leukocytosis. Three patients in the pegfilgrastim 6.0-mg group experienced enterocolitis, FN, and uterine leiomyoma (one AE in each patient). Four (1.9\%) patients experienced AEs leading to discontinuation. Of these patients, one pegfilgrastim patient discontinued in cycle 1 because of headache, malaise, and discomfort; however, the main reason for discontinuation was withdrawal of informed consent. One lipegfilgrastim $3.0-\mathrm{mg}$ patient discontinued in cycle 3 because of pyrexia, one lipegfilgrastim 4.5-mg patient discontinued in cycle 2 because of pneumonia, and one 
lipegfilgrastim 4.5-mg patient discontinued in cycle 3 because of thrombocytopenia, FN, mucosal inflammation, and hemorrhagic disorder.

Laboratory assessments were consistent with the underlying disease and the chemotherapy received, and did not give rise to any safety concerns.

\section{Discussion}

In the present dose-finding study, patients experienced a dose-dependent decrease in DSN during cycle 1 with increasing lipegfilgrastim doses, with the most effective dose being lipegfilgrastim $6.0 \mathrm{mg}$. In addition, lipegfilgrastim $6.0 \mathrm{mg}$ had comparable efficacy with pegfilgrastim $6.0 \mathrm{mg}$, for the DSN during cycle 1 . Post-hoc analyses confirmed that lipegfilgrastim $6.0 \mathrm{mg}$ was non-inferior to pegfilgrastim $6.0 \mathrm{mg}$ for reducing cycle $1 \mathrm{DSN}$ in patients with breast cancer receiving doxorubicin and docetaxel chemotherapy. The DSN in cycle 1 for patients treated with lipegfilgrastim $6.0 \mathrm{mg}$ and pegfilgrastim was 0.76 and 0.87 days, respectively. This is shorter than that previously reported for pegfilgrastim in patients with breast cancer receiving this chemotherapy regimen (mean DSN, 1.3-1.8 days) $[1,9,16]$. However, unlike previous studies, the present study only included chemotherapy-naive patients, which may have contributed to the slightly shorter DSN.

The incidence of severe neutropenia in cycle 1 was $\approx 50 \%$ in the lipegfilgrastim 3.0 - and 4.5 -mg groups and in the pegfilgrastim group. The incidence was lower in the lipegfilgrastim 6.0-mg group (38\%), which further supports the use of this dose in clinical studies. Based on the definition of ANC $<0.5 \times 10^{9} / \mathrm{L}$ and a fever $>38.5{ }^{\circ} \mathrm{C}$, only one patient in the pegfilgrastim group experienced FN. The incidence of $\mathrm{FN}$ was lower than that previously reported for patients treated with pegfilgrastim (9-12\%) receiving the same chemotherapy regimen $[1,9,16]$. The incidence of FN was considerably lower than that of patients receiving doxorubicin and docetaxel chemotherapy without G-CSF support reported in a previous study wherein $40 \%$ of patients experienced $\mathrm{FN}$ defined as any grade 3 or 4 neutropenia plus fever $\left(>38^{\circ} \mathrm{C}\right)$ requiring antibiotics [17]. In addition, in a previous study using the same chemotherapy regimen and similar inclusion and exclusion criteria as the current study, incidence of FN during cycle 1 was reduced by about two-thirds, from $36 \%$ in placebo patients to $\approx 12 \%$ in patients receiving G-CSF support [15]; the incidence was still higher than that observed in the present study.

A dose-dependent trend for improved efficacy with increasing lipegfilgrastim doses was apparent for most secondary efficacy measures, including DSN cycles 3 and 4, mean time to ANC nadir, depth of ANC nadir, and ANC recovery. In addition, significant differences between lipegfilgrastim $6.0 \mathrm{mg}$ and pegfilgrastim were observed for several secondary efficacy measures; however, these data should be interpreted with caution, because the observed differences were small and the clinical relevance has not been confirmed.

The design of the current study compares well with previously published pivotal pegfilgrastim studies in breast cancer patients receiving doxorubicin $60 \mathrm{mg} / \mathrm{m}^{2}$ and docetaxel $75 \mathrm{mg} / \mathrm{m}^{2}$ every 3 weeks for 4 cycles $[1,9,16]$. In the present study, the highly myelotoxic doxorubicin and docetaxel regimen was chosen to assess lipegfilgrastim efficacy to prevent severe neutropenia because this chemotherapy regimen is associated with a risk of $\mathrm{FN}$ of approximately 35-40\% [15, 17], and G-CSF support is clearly indicated $[2,5]$. Breast cancer patients were chosen because they represent a main cancer type in which G-CSF is used, and because breast cancer patients were studied in pivotal and dose-finding pegfilgrastim studies [1, 9, 16, 18].

While the present study only evaluated the efficacy and safety of lipegfilgrastim in breast cancer patients, results suggest that the potential for lipegfilgrastim to prevent severe neutropenia may extend beyond this cancer type to patients receiving myelosuppressive therapy. Pegfilgrastim has been effective in reducing chemotherapy-induced neutropenia in patients with breast cancer, colorectal cancer, lymphoma, lung cancer, and various other solid tumors [19-21]. In addition, tbo-filgrastim, a short-acting recombinant G-CSF, has demonstrated comparable efficacy to filgrastim for prophylaxis of chemotherapy-induced neutropenia in patients with breast cancer, lung cancer, and non-Hodgkin lymphoma [22].

Lipegfilgrastim PK results demonstrated a general dosedependent increase in drug exposure, reflected by increasing $C_{\max }$ and AUC values with increasing dose. The period of sustained G-CSF concentrations coincided with the ANC nadir, supporting the hypothesis that lipegfilgrastim has the same neutrophil-mediated clearance mechanism of elimination as pegfilgrastim. This self-regulating property means that a single dose can provide sufficient neutrophil support for different durations of neutropenia [7, 16].

The safety profiles of lipegfilgrastim $6.0 \mathrm{mg}$ and pegfilgrastim $6.0 \mathrm{mg}$ were comparable, and safety events were not dose related. The incidence of TEAEs was expected in this patient population and consistent with the underlying disease and concomitant chemotherapy. No unexpected new findings were observed. Bone pain was the most common TEADR and is known to be associated with G-CSF treatment. Fatigue, the second most common TEADR, is frequently reported during chemotherapy.

In conclusion, lipegfilgrastim is a safe and effective G-CSF support treatment in breast cancer patients receiving myelosuppressive chemotherapy with doxorubicin and docetaxel. Lipegfilgrastim $6.0 \mathrm{mg}$, which is at least 
equivalent to the standard 6.0-mg fixed dose of pegfilgrastim with regard to DSN in this patient population, is the optimal fixed dose for evaluation in phase 3 studies.

Acknowledgments The authors thank Lisa Grauer, MSc (Chameleon Communications, New York, NY) and Lisa Feder, PhD (Peloton Advantage, LLC, Parsippany, NJ) for their medical writing and editorial assistance in the development of this manuscript. This study was supported by Teva Pharmaceutical Industries Ltd, Petach Tikva, Israel.

Conflict of interest Anton Buchner, Reiner Elsässer, and Peter Bias are employees of Teva Pharmaceutical Industries Ltd.

Open Access This article is distributed under the terms of the Creative Commons Attribution Noncommercial License which permits any noncommercial use, distribution, and reproduction in any medium, provided the original author(s) and the source are credited.

\section{References}

1. Holmes FA, O'Shaughnessy JA, Vukelja S, Jones SE, Shogan J, Savin M, Glaspy J, Moore M, Meza L, Wiznitzer I, Neumann TA, Hill LR, Liang BC (2002) Blinded, randomized, multicenter study to evaluate single administration pegfilgrastim once per cycle versus daily filgrastim as an adjunct to chemotherapy in patients with high-risk stage II or stage III/IV breast cancer. J Clin Oncol 20:727-731

2. Aapro MS, Bohlius J, Cameron DA, Dal Lago L, Donnelly JP, Kearney N, Lyman GH, Pettengell R, Tjan-Heijnen VC, Walewski J, Weber DC, Zielinski C, The European Organisation for Research and Treatment of Cancer (2011) 2010 update of EORTC guidelines for the use of granulocyte-colony stimulating factor to reduce the incidence of chemotherapy induced febrile neutropenia in adult patients with lymphoproliferative disorders and solid tumours. Eur J Cancer 47:8-32

3. Page AV, Liles WC (2011) Colony-stimulating factors in the prevention and management of infectious diseases. Infect Dis Clin N Am 25:803-817

4. NCCN Clinical Practice Guidelines in Oncology. Myeloid Growth Factors v.2.2013 (2013) Fort Washington, PA: National Comprehensive Cancer Network. Available at: www.nccn.org. Accessed 28 May 2014

5. Smith TJ, Khatcheressian J, Lyman GH, Ozer H, Armitage JO, Balducci L, Bennett CL, Cantor SB, Crawford J, Cross SJ, Demetri G, Desch CE, Pizzo PA, Schiffer CA, Schwartzberg L, Somerfield MR, Somlo G, Wade JC, Wade JL, Winn RJ, Wozniak AJ, Wolff AC (2006) 2006 update of recommendations for the use of white blood cell growth factors: an evidence-based, clinical practice guideline. J Clin Oncol 24:3187-3205

6. Gascon P (2012) Presently available biosimilars in hematologyoncology: G-CSF. Target Oncol 7(suppl 1):S29-S34

7. Yang BB, Kido A (2011) Pharmacokinetics and pharmacodynamics of pegfilgrastim. Clin Pharmacokin 50:295-306

8. von Minckwitz G, Schwenkglenks M, Skacel T, Lyman GH, Pousa AL, Bacon P, Easton V, Aapro MS (2009) Febrile neutropenia and related complications in breast cancer patients receiving pegfilgrastim primary prophylaxis versus current practice neutropenia management: results from an integrated analysis. Eur J Cancer 45:608-617

9. Green MD, Koelbl H, Baselga J, Galid A, Guillem V, Gascon P, Siena S, Lalisang RI, Samonigg H, Clemens MR, Zani V, Liang BC, Renwick J, Piccart MJ, The International Pegfilgrastim 749 Study Group (2003) A randomized double-blind multicenter phase III study of fixed-dose single-administration pegfilgrastim versus daily filgrastim in patients receiving myelosuppressive chemotherapy. Ann Oncol 14:29-35

10. Lonquex: Summary of Product Characteristics. London: European Medicines Agency; 2013

11. Bondarenko I, Bias P, Elsasser R, Buchner A (2013) Incidence of bone pain in patients with breast cancer treated with lipegfilgrastim or pegfilgrastim: an integrated analysis from phase II and III studies [poster P162]. Presented at: Biennial European Multidisciplinary Cancer Congress, Amsterdam, The Netherlands, September 27-October 1, 2013

12. De Naurois J, Novitzky-Basso I, Gill MJ, Marti FM, Cullen MH, Roila F, The ESMO Guidelines Working Group (2010) Management of febrile neutropenia: ESMO clinical practice guidelines. Ann Oncol 21(suppl 5):v252-v256

13. European Medicines Agency (2007) Guideline on clinical trials with haematopoietic growth factors for the prophylaxis of infection following myelosuppressive or myeloablative therapy. EMEA/CPMO/555/95 Rev. 1. Available at: www.ema.europa. eu/docs/en_GB/document_library/Scientific_guideline/2009/12/ WC500017738.pdf. Accessed 28 May 2014

14. Edge S, Byrd, Compton CC, Fritz AG, Greene FL, Trotti A (2011) AJCC cancer staging manual, 7th edn. Springer, New York

15. del Giglio A, Eniu A, Ganea-Motan D, Topuzov E, Lubenau H (2008) XM02 is superior to placebo and equivalent to Neupogen in reducing the duration of severe neutropenia and the incidence of febrile neutropenia in cycle 1 in breast cancer patients receiving docetaxel/doxorubicin chemotherapy. BMC Cancer $8: 332-338$

16. Holmes FA, Jones SE, O'Shaughnessy J, Vukelja S, George T, Savin M, Richards D, Glaspy J, Meza L, Cohen G, Dhami M, Budman DR, Hackett J, Brassard M, Yang BB, Liang BC (2002) Comparable efficacy and safety profiles of once-per-cycle pegfilgrastim and daily injection filgrastim in chemotherapy-induced neutropenia: a multicenter dose-finding study in women with breast cancer. Ann Oncol 13:903-909

17. Brain EG, Bachelot T, Serin D, Kirscher S, Graic Y, Eymard JC, Extra JM, Combe M, Fourme E, Noguès C, Rouëssé J, The RAPP-01 Trial Investigators (2005) Life-threatening sepsis associated with adjuvant doxorubicin plus docetaxel for intermediate-risk breast cancer. JAMA 293:2367-2371

18. Vogel CL, Wojtukiewicz MZ, Carroll RR, Tjulandin SA, Barajas-Figueroa LJ, Wiens BL, Neumann TA, Schwartzberg LS (2005) First and subsequent cycle use of pegfilgrastim prevents febrile neutropenia in patients with breast cancer: a multicenter, double-blind, placebo-controlled phase III study. J Clin Oncol 23:1178-1184

19. Cooper KL, Madan J, Whyte S, Stevenson MD, Akehurst RL (2011) Granulocyte colony-stimulating factors for febrile neutropenia prophylaxis following chemotherapy: systematic review and meta-analysis. BMC Cancer 11:404

20. Pinto L, Liu Z, Doan Q, Bernal M, Dubois R, Lyman G (2007) Comparison of pegfilgrastim with filgrastim on febrile neutropenia, grade IV neutropenia and bone pain: a meta-analysis of randomized controlled trials. Curr Med Res Opin 23:2283-2295

21. Tan H, Tomic K, Hurley D, Daniel G, Barron R, Malin J (2011) Comparative effectiveness of colony-stimulating factors for febrile neutropenia: a retrospective study. Curr Med Res Opin 27:79-86

22. Engert A, delGiglio A, Bias P, Lubenau H, Gatzemeier U, Heigener D (2009) Incidence of febrile neutropenia and myelotoxicity of chemotherapy: a meta-analysis of biosimilar G-CSF studies in breast cancer, lung cancer, and non-Hodgkin's lymphoma. Onkologie 32:599-604 